\title{
Caracterização e influência de rizóbios isolados de alfafa na germinação e desenvolvimento inicial de plântulas de arroz
}

\author{
Characterization and influence of alfafa rhizobia on germination and early growth of rice seedling
}

\author{
Marcos Roberto Dobler Stroschein ${ }^{{ }^{*}}$ Enilson Luiz Saccol de Sá ${ }^{I I}$ Rafael Goulart Machado ${ }^{\mathrm{I}}$

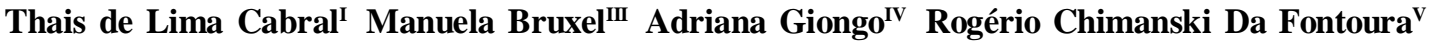

RESUMO

A inoculação de plantas leguminosas com rizóbios é um dos principais métodos biotecnológicos de utilização de micro-organismos em plantas visando à fixação biológica de nitrogênio na agricultura. No entanto, nos últimos anos, vêm sendo observada nesses micro-organismos a capacidade de produção de fitohormônios, principalmente o ácido indolacético (AIA) e a promoção de crescimento em gramíneas. Dessa forma, os objetivos deste trabalho foram quantificar o ácido indol-acético produzido por rizóbios isolados de alfafa, avaliar o efeito da inoculação desses micro-organismos na germinação de sementes de arroz e realizar a caracterização genética desses isolados. Nove rizóbios isolados de nódulos de alfafa foram avaliados quanto a sua capacidade de produção de equivalentes de AIA e a influência da inoculação desses micro-organismos na germinação e desenvolvimento de plântulas de arroz. Os rizóbios produtores de AIA foram identificados pelo sequenciamento da região do gene $16 \mathrm{~S}$ do DNAr. A produção de equivalentes ao ácido indol-acético foi observada em todos rizóbios, com valores que variaram de

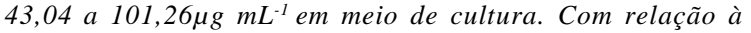
germinação das sementes de arroz, a inoculação com rizóbios acelerou o processo e o crescimento de suas plântulas. Os rizóbios UFRGS Ms58, Ms515, Ms195, Ms205, Ms2010 e 2012 foram identificados como pertencentes à espécie Sinorhizobium meliloti e UFRGS Ms55, Ms72 e Ms75 à espécie Rhizobium sp.

Palavras-chave: rizobactéria, promoção de crescimento, ácido indol-acético, caracterização genética, Oriza sativa.

\begin{abstract}
The inoculation of leguminous plants with rhizobia is one of the main methods of biotechnological use of microorganisms in order to obtain biological nitrogen fixation in agriculture. However, in recent years it has been attributed to these microorganisms the ability to produce phytohormones, mainly indole acetic acid (IAA), and to promote the growth in grasses. Thus, the objectives of this study were to quantify the indole acetic acid produced by rhizobia from alfalfa and to evaluate the effect of inoculation of these microorganisms on the germination of rice seed and to perform the genetic characterization of these isolates. Nine rhizobia, from nodules of alfalfa, were evaluated for their ability to produce IAA equivalents and for their influence in inoculating these microorganisms on germination and seedling development of rice. Moreover, these rhizobia producers of IAA were identified by the 165 region of DNAr. The equivalent production of indole acetic acid was observed in all tested isolates, with values ranging from 43.04 to $101.26 \mu \mathrm{g} \mathrm{mL}^{-1}$ in culture medium. Regarding the germination of rice seeds, the inoculation with rhizobia accelerated this germination and its growth. Microorganisms UFRGS Ms58, UFRGS Ms515, UFRGS Ms195, UFRGS Ms205, UFRGS Ms2010 and UFRGS 2012 were identified as belonging to the species of Sinorhizobium meliloti. Microorganisms Ms55 UFRGS, UFRGS Ms75 and UFRG Ms72 were identified as belonging to the species of Rhizobium $s p$.
\end{abstract}

Key words: rhizobacteria, plant growth promotion, indole acetic acid, the genetic characterization, Oriza sativa.

\footnotetext{
'Programa de Pós-graduação em Ciência do Solo, Universidade Federal do Rio Grande do Sul (UFRGS), Av. Bento Gonçalves, 7712 91540-000, Porto Alegre, RS, Brasil. E-mail: marcosstroschein@yahoo.com.br. Autor para correspondência.

"Departamento de Solos, UFRGS, Porto Alegre, RS, Brasil.

IIIPrograma de Pós-graduação em Microbiologia Agrícola, UFRGS, Porto Alegre, RS, Brasil.

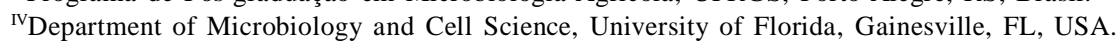

${ }^{\mathrm{v}}$ Curso de Agronomia, UFRGS, Porto Alegre, RS, Brasil.
} 


\section{INTRODUÇÃO}

A sustentabilidade da exploração dos recursos naturais é um dos principais desafios da agricultura moderna, cujo uso de micro-organismos vem sendo apontado como uma alternativa para o menor uso de insumos no incremento da produção agrícola, sendo a inoculação de leguminosas com rizóbios e a utilização de micorrizas em mudas de diferentes espécies os exemplos mais notáveis. No entanto, nas últimas décadas, outros micro-organismos têm atraído a atenção dos pesquisadores, com vista a uma potencial utilização na agricultura (VARGAS et al., 2009). As bactérias presentes na rizosfera são capazes de contribuir para o aumento da produtividade de algumas lavouras devido à colonização das raízes e estímulo ao crescimento das plantas. Esses microorganismos são conhecidos como rizobactérias promotoras de crescimento vegetal (Plant growthpromoting rhizobacteria - PGPR) (BISWAS et al., 2000).

Diversos micro-organismos vêm sendo relatados como promotores de crescimento em plantas, que incluem os gêneros Azoarcus, Azospirillum, Azotobacter, Arthrobacter, Bacillus, Clostridium, Enterobacter, Gluconacetobacter, Pseudomonas e Serratia, os quais são exclusivamente microorganismos não simbióticos (VARGAS et al., 2009). Além desses micro-organismos, estudos comprovaram a ação benéfica de rizóbios na atividade de promoção de crescimento vegetal em diversas espécies de plantas, a exemplo de milho, sorgo, milheto, canola, alface, mostarda, arroz, cevada (MATIRU \& DAKORA, 2004; PERRINE-WALKER et al., 2007). Os detalhes dos mecanismos da interação entre rizóbios e nãoleguminosas ainda é pouco entendido, no entanto, a capacidade de produção de fitohormônios, como o ácido indol-acético (AIA), vem sendo relatada como uma das possíveis formas de estímulo ao crescimento vegetal (CHEN et al., 2005; BANERJEE et al., 2006).

O ácido indol-acético, fitohormônio pertencente ao grupo das auxinas, atua na elongação das células vegetais, na formação das raízes laterais e pêlos radiculares, bem como na germinação das sementes (BISWAS et al., 2000). Nas fases iniciais do desenvolvimento das plantas, a inoculação de rizóbios produtores de AIA pode aumentar a velocidade da germinação das sementes inoculadas, como observado em arroze alface (SCHLINDWEIN et al., 2008; VARGAS et al., 2009; PALANIAPPAN et al., 2010).

Dessa forma, os objetivos deste trabalho foram quantificar o ácido indol-acético produzido por rizóbios isolados de alfafa, avaliar o efeito da inoculação desses micro-organismos na germinação de sementes de arroz e realizar a caracterização genética desses isolados.

\section{MATERIAL E MÉTODOS}

Os rizóbios estudados foram obtidos da coleção de culturas da Universidade Federal do Rio Grande do Sul, sendo escolhidos nove rizóbios que produziam equivalentes ao ácido indol-acético em meio de cultura. A estirpe SEMIA 816 e o isolado de Lotus corniculatus UFRGS Lc348 foram usados como referência na quantificação do ácido indol-acético (OSORIO FILHO, 2009). Os testes de germinação das sementes foram realizados com a espécie Oriza sativa cultivar 'IRGA 409'.

A quantificação da produção de auxinas equivalentes ao ácido indol-acético pelas bactérias selecionadas foi realizada utilizando-se o método de ASGHAR et al. (2002). As concentrações de ácido indolacético foram determinadas em espectrofotômetro com comprimento de onda de 530nm (GORDON \& WEBER, 1951), em comparação com uma curva com os seguintes valores: $0,0,2,1,2,3,6,11,15,20,45,100,200$ e $300 \mu \mathrm{g}$ $\mathrm{mL}^{-1}$ de AIA sintético.

Na avaliação do efeito dos rizóbios sobre a germinação de sementes de arroz, foram utilizadas sementes da cultivar 'IRGA 409' submetidas previamente à assepsia com álcool $70 \%$ (1min.) e hipoclorito de sódio (2,5\%) (1min), seguida de cinco lavagens com água esterilizada. Os testes foram conduzidos em placas de Petri, em quatro repetições e 36 sementes em cada placa, sendo o delineamento inteiramente ao acaso e as médias comparadas pelo teste de Scott Knott a 5\% de probabilidade de erro. Os tratamentos foram nove rizóbios isolados de alfafa (UFRGS Ms205, UFRGS Ms75, UFRGS Ms72, UFRGS Ms55, UFRGS Ms58, UFRGS Ms2010, UFRGS Ms2012, UFRGS Ms515 e UFRGS Ms195) e duas testemunhas, a estirpe SEMIA 816 e o isolado de Lotus corniculatus UFRGS Lc348. As sementes foram colocadas sobre papel toalha previamente esterilizados, sendo umedecidos com $10 \mathrm{~mL}$ de meio de cultura LM estéril (tratamento não inoculado - controle). As placas contendo as sementes inoculadas foram mantidas no escuro, em uma estufa bacteriológica, à temperatura de $28^{\circ} \mathrm{C}$, por um período de sete dias. Do segundo, quarto e sexto dia após a inoculação das sementes com os rizóbios nas placas de Petri, foi determinado o percentual de germinação. $O$ índice de velocidade de germinação (IVG) foi calculado pela soma do número de sementes germinadas a cada dia e dividido pelo respectivo número de dias transcorridos a partir da 
instalação do teste, conforme MAGUIRE (1962). O comprimento da raiz principal e parte aérea das plântulas de arroz foram determinados aos dois e seis dias após a emergência, em câmara de fluxo laminar, sendo medidas 10 plântulas de cada repetição, com auxílio de uma régua.

A região de DNA do gene que codifica a porção $16 \mathrm{~S}$ do ribossomo foi amplificada com os oligonucleotídeo 8F (AGAGTTTGATCCTTGGCTCAG) e 1492R (GCYTACCTTGTT-ACGACTT) (EDWARDS et al., 1989). Os ciclos empregados foram: um cicloinicial a $95^{\circ} \mathrm{C}$ por $3 \mathrm{~min}, 35$ ciclos de desnaturação em $94^{\circ} \mathrm{C}$ por $1 \mathrm{~min}$, anelamento em $55^{\circ} \mathrm{C}$ por $1 \mathrm{~min}$, extensão em $72^{\circ} \mathrm{C}$ para $2 \mathrm{~min}$ e um ciclo final de extensão em $72^{\circ} \mathrm{C}$ por $3 \mathrm{~min}$. Os fragmentos foram sequenciados usando o sistema de eletroforese por capilaridade MegaBace 500 (Amersham Biosciences) e as sequências obtidas foram adicionadas ao GenBank (UFRGS Ms55: JF693274; UFRGS Ms58: JF693275; UFRGS Ms515: JF693273; UFRGS Ms75: JF693278; UFRGS Ms72: JF693277; UFRGS Ms195: JF693268; UFRGS Ms205: JF693272; UFRGS Ms2012: JF693269). As sequências parciais da região 16S DNAr das estirpes homólogas foram pesquisadas no GenBank com o programa BLAST 2.0, analisadas pelo algoritmo Megablast e usadas para a construção da árvore filogenética. As sequências selecionadas foram alinhadas pelo algoritmo ClustalW e as relações filogenéticas foram analisadas usandose o método Neighbor-joining, realizado pelo programa MEGA4.0 (TAMURA et al., 2007).

\section{RESULTADOS E DISCUSSÃO}

A produção de substâncias equivalentes ao ácido indol-acético foi observada em todos os isolados testados, com valores que variaram de 43,04 a 101,26 $\mu \mathrm{g}$ $\mathrm{mL}^{-1}$ de equivalente ao ácido indol-acético (AIA) em meio de cultura (Tabela 1). Os isolados UFRGS Ms205, Ms75, Ms72, Ms55 e Ms58 produziram quantidades de AIA em meio de cultura superiores aos dois controles testados. Valores superiores a $100 \mu \mathrm{g} \mathrm{mL}^{-1}$ foram observados para isolados de rizóbios, como os microorganismos estudados por CHAGAS Jr. et al. (2009).

Todos os rizóbios inoculados nas sementes de arroz promoveram um aumento inicial na porcentagem de germinação a partir do segundo dia após a inoculação, em comparação ao tratamento controle (não inoculado), sendo que, para as sementes inoculadas com o isolado UFRGS Ms72, observou-se a maior porcentagem de geminação inicial (Tabela 1). As porcentagens de germinação final não diferiram significativamente entre os tratamentos inoculados e o controle (Tabela 1). $\mathrm{O}$ aumento da germinação inicial favoreceu o índice de velocidade da germinação (IVG) das sementes inoculadas com rizóbios, sendo que quando se utilizou os isolados UFRGS Ms72 e UFRGS Ms205 ocorreram os maiores índices de velocidade de germinação (Tabela 1). Incrementos da germinação inicial e aumentos da velocidade de germinação de sementes inoculadas com rizóbios produtores de AIA foram relatados por BISWAS et al. (2000), GUPTA et al. (2002), PANDEY et al. (2005), SCHLINDWEIN et al. (2008), VARGAS et al. (2009) e OSORIO FILHO (2009), sendo esse fator importante no estabelecimento da cultura.

A inoculação dos rizóbios em sementes de arroz também induziu mudanças no comprimento da raiz e da parte aérea das plântulas (Tabela 2). Cinco

Tabela 1 - Quantificação de substâncias equivalentes ao ácido indol-acético (AIA) produzidas por rizóbios em meio LM enriquecido com triptofano, germinação inicial e final de sementes de arroz e índice de velocidade de germinação (IVG).

\begin{tabular}{|c|c|c|c|c|}
\hline Rizóbios & $\mathrm{AIA}\left(\mu \mathrm{g} \mathrm{mL}^{-1}\right)$ & Germinação inicial \% & Germinação final \% & IVG \\
\hline UFRGS Ms72 & $95,6 \mathrm{a}$ & $25,0 a^{*}$ & $95,1^{\mathrm{ns}}$ & $23,0 \mathrm{a}$ \\
\hline UFRGS Ms205 & $101,3 \mathrm{a}$ & $18,8 \mathrm{~b}$ & 100,0 & $23,0 \mathrm{a}$ \\
\hline UFRGS Ms55 & $92,0 \mathrm{a}$ & $18,8 \mathrm{~b}$ & 93,1 & $21,3 \mathrm{~b}$ \\
\hline UFRGS Ms2012 & $56,7 \mathrm{~b}$ & $18,8 \mathrm{~b}$ & 98,9 & $20,5 b$ \\
\hline UFRGS Ms195 & $55,6 \mathrm{~b}$ & $18,8 \mathrm{~b}$ & 98,9 & $20,5 \mathrm{~b}$ \\
\hline SEMIA 816 & $55,0 \mathrm{~b}$ & $18,8 \mathrm{~b}$ & 98,9 & $20,5 b$ \\
\hline UFRGS Ms515 & $55,8 \mathrm{~b}$ & $17,4 \mathrm{~b}$ & 92,6 & $20,1 \mathrm{~b}$ \\
\hline UFRGS Lc 348 & $43,0 \mathrm{c}$ & $16,0 \mathrm{~b}$ & 95,6 & $20,1 \mathrm{~b}$ \\
\hline UFRGS Ms58 & $84,4 \mathrm{a}$ & $16,0 \mathrm{~b}$ & 100,0 & $20,1 \mathrm{~b}$ \\
\hline UFRGS Ms2010 & $59,3 \mathrm{~b}$ & $16,0 \mathrm{~b}$ & 95,4 & $20,1 \mathrm{~b}$ \\
\hline UFRGS Ms75 & $100,3 \mathrm{a}$ & $14,8 \mathrm{~b}$ & 97,2 & $20,1 \mathrm{~b}$ \\
\hline Controle & - & $3,5 \mathrm{c}$ & 99,6 & $17,6 \mathrm{c}$ \\
\hline $\mathrm{CV}(\%)$ & 10,1 & 26,3 & - & 7,2 \\
\hline
\end{tabular}

* Médias seguidas da mesma letra não diferem entre si pelo teste de Scott Knott a 5\% de probabilidade de erro. ${ }^{\text {ns: }}$ não significativo. 
Tabela 2 - Influência da inoculação com diferentes isolados de rizóbios produtores de AIA sobre o crescimento de plântulas de arroz.

\begin{tabular}{|c|c|c|c|c|}
\hline Rizóbios & $2^{\mathrm{o}}$ dia & $6^{\circ}$ dia & $2^{o}$ dia & $6^{-}$dia \\
\hline UFRGSMs75 & $24 \mathrm{a}^{*}$ & $48 \mathrm{a}$ & $27 \mathrm{a}$ & $59 \mathrm{a}$ \\
\hline UFRGSMs72 & $26 \mathrm{a}$ & $53 \mathrm{a}$ & $28 \mathrm{a}$ & $61 \mathrm{a}$ \\
\hline UFRGSMs205 & $21 b$ & $44 \mathrm{~b}$ & $27 \mathrm{a}$ & $54 \mathrm{~b}$ \\
\hline UFRGSMs55 & $18 \mathrm{~b}$ & $42 \mathrm{~b}$ & $21 \mathrm{~b}$ & $54 \mathrm{~b}$ \\
\hline UFRGSMs515 & $20 \mathrm{~b}$ & $45 \mathrm{~b}$ & $23 \mathrm{~b}$ & $55 \mathrm{~b}$ \\
\hline UFRGS Lc 348 & $16 \mathrm{c}$ & $44 \mathrm{~b}$ & $19 \mathrm{~b}$ & $55 \mathrm{~b}$ \\
\hline UFRGSMs58 & $14 \mathrm{c}$ & $40 \mathrm{c}$ & $19 \mathrm{~b}$ & $50 \mathrm{c}$ \\
\hline UFRGSMs2010 & $15 \mathrm{c}$ & $40 \mathrm{c}$ & $18 \mathrm{~b}$ & $49 \mathrm{c}$ \\
\hline UFRGSMs2012 & $14 \mathrm{c}$ & $40 \mathrm{c}$ & $17 \mathrm{c}$ & $49 \mathrm{c}$ \\
\hline UFRGSMs195 & $13 \mathrm{c}$ & $39 \mathrm{c}$ & $17 \mathrm{c}$ & $49 \mathrm{c}$ \\
\hline SEMIA 816 & $12 \mathrm{c}$ & $41 \mathrm{~b}$ & $16 \mathrm{c}$ & $51 \mathrm{c}$ \\
\hline $\mathrm{NI}$ & $11 \mathrm{c}$ & $39 \mathrm{c}$ & $14 \mathrm{c}$ & $48 \mathrm{c}$ \\
\hline $\mathrm{CV}(\%)$ & 19,9 & 16,9 & 18,1 & 17,2 \\
\hline
\end{tabular}

* Médias seguidas da mesma letra na coluna não diferem entre si pelo teste de Scott Knott a 5\% de probabilidade de erro.

isolados de alfafa (UFRGS Ms72, Ms75, Ms205, Ms55, Ms515) promoveram aumento no tamanho da raiz no segundo e sexto dia após a inoculação, sendo que, nas sementes inoculadas com os isolados UFRGS Ms72 e Ms75, constataram-se os maiores valores de comprimento de raiz. O isolado de Lotus corniculatus usado nesse experimento como referência promoveu aumento no tamanho da raiz no sexto dia após a inoculação. Os isolados (UFRGS Ms75 e UFRGS Ms72) inoculados em sementes de arroz promoveram os maiores aumentos no comprimento da parte aérea das plântulas (Tabela 2). A promoção do crescimento de plântulas inoculadas com rizóbios promotores de crescimento foi descrita por BISWAS et al. (2000) e VARGAS et al. (2009).

Com relação à análise filogenética, a amplificação da região 16S do DNA ribossomal dos rizóbios isolados de alfafa produtores de ácido indolacético com os oligonucleotídeos $8 \mathrm{~F}$ e $1492 \mathrm{R}$ foi de aproximadamente $1000 \mathrm{bp}$ para todas as bactérias sequenciadas (Tabela 3). Fragmentos com esse tamanho têm sido considerados suficientes para se realizar a identificação correta de procariotos (TRÜPER et al., 2006), por abranger quase todo o tamanho esperado do gene 16S do DNA ribossomal (WEISBURG et al., 1991).

A partir dos dados do sequenciamento dos nucleotídeos do fragmento obtido da amplificação da região 16S DNAr dos isolados mais eficientes avaliados nesse estudo e de representantes dos gêneros Sinorhizobium, Rhizobium Mesorhizobium e Bradyrhizobium, foi possível construir uma árvore filogenética (Figura 1). A análise filogenética das sequências obtidas com as depositadas no banco de

Tabela 3 - Identificação de rizóbios isolados de alfafa produtores de ácido indol-acético pelo sequenciamento da região 16S DNAr.

\begin{tabular}{|c|c|c|c|c|}
\hline \multirow{2}{*}{ Isolados } & \multirow{2}{*}{$\begin{array}{l}\text { Comprimento do gene } \\
\qquad(\mathrm{pb})\end{array}$} & \multirow{2}{*}{ Número de acesso } & \multicolumn{2}{|c|}{ 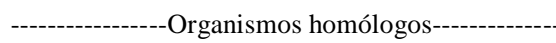 } \\
\hline & & & Espécie & Identidade $(\%)$ \\
\hline UFRGSMs55 & 1012 & JF693274 & Rhizobium sp. & 100 \\
\hline UFRGSMs58 & 1004 & JF693275 & Sinorhizobium meliloti & 99 \\
\hline UFRGSMs515 & 1017 & JF693273 & Sinorhizobium meliloti & 99 \\
\hline UFRGSMs75 & 923 & JF693278 & Rhizobium sp. & 100 \\
\hline UFRGSMs72 & 1008 & JF693277 & Rhizobium sp. & 100 \\
\hline UFRGSMs195 & 985 & JF693268 & Sinorhizobium meliloti & 99 \\
\hline UFRGSMs205 & 1012 & JF693272 & Sinorhizobium meliloti & 99 \\
\hline UFRGSMs2010 & 978 & JF693269 & Sinorhizobium meliloti & 99 \\
\hline UFRGSMs2012 & 983 & JF693270 & Sinorhizobium meliloti & 99 \\
\hline
\end{tabular}

Ciência Rural, v.41, n.10, out, 2011. 


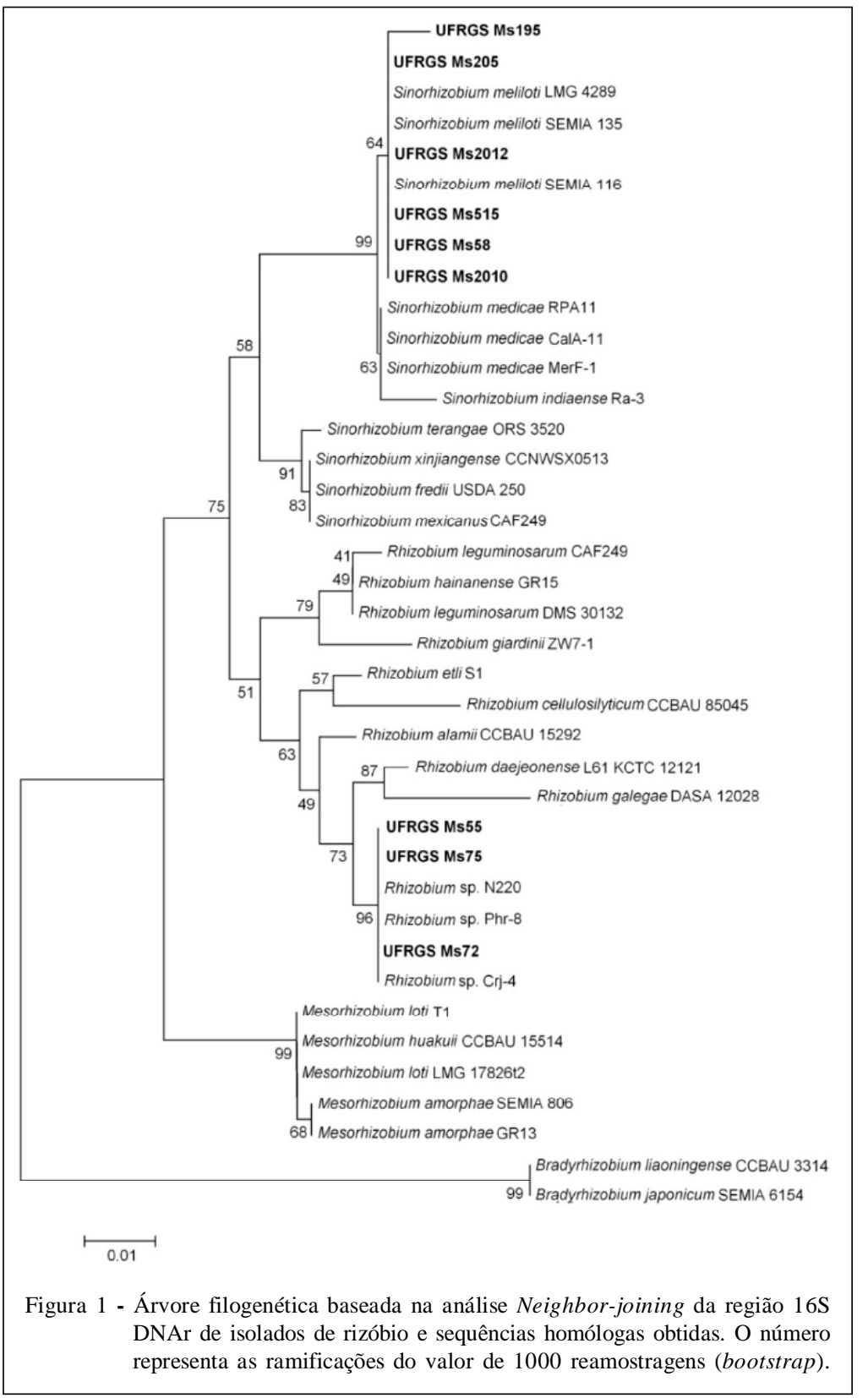

dados do GenBank revelou que os isolados UFRGS Ms195, Ms2012, Ms515, Ms58 e Ms210 foram identificados como pertencentes à espécie Sinorhizobium melilot e os isolados UFRGS Ms72, Ms75 e UFRGS Ms55 foram identificados como pertencentes ao gênero Rhizobium (Figura 1). A identificação do gênero Rhizobium para bactérias isoladas de nódulos de alfafa foi descrita por BROMFIELD et al. (2010).

\section{CONCLUSÃO}

Todos os micro-organismos testados produzem substâncias equivalentes ao ácido indol- acético, sendo que a inoculação com rizóbios acelera o processo de germinação das sementes e o crescimento das plântulas de arroz. Os rizóbios UFRGS Ms58, UFRGS Ms515, UFRGS Ms195 UFRGS Ms205, UFRGS Ms2010 e UFRGS 2012 pertencem à espécie Sinorhizobium meliloti e os rizóbios UFRGS Ms55, UFRGS Ms72 e UFRGS Ms75 ao gênero Rhizobium.

\section{REFERÊNCIAS}

ASGHAR, H.N. et al. Relationship between in vitro production of auxins by rhizobacteria and their growth-promoting activities in Brassica juncea L. Biology and Fertility of Soils, Berlin, v.35, n.4, p.231-237, 2002. Disponível em: <http://

Ciência Rural, v.41, n.10, out, 2011. 
www.scielo.br/revistas/cr/pinstruc.htm>. Acesso em: 13 jun. 2009. doi: 10.1007/s00374-002-0462-8.

BANERJEE, M.R. Plant-growth-promoting rhizobacteria as biofertilizers and biopesticides. In. RAI, M.K. (Ed). Handbook of microbial biofertilizers. New York: Food Products, 2006. p.137-181.

BISWAS, J. et al. Rhizobial inoculation influences seedling vigor and yield of rice. Agronomy Journal, Madison, v.92, n.5, p.880-886, 2000. Disponível em: <http://www.crops.org/ publications/aj/articles/92/5/880>. Acesso em: 13 jun. 2009. doi: $10.2134 /$ agronj2000.925880x.

BROMFIELD, E.S.P. et al. Ensifer, Phyllobacterium and Rhizobium species occupy nodules of Medicago sativa (alfalfa) and Melilotus alba (sweet clover) grown at a Canadian site without a history of cultivation. Microbiology, Madison, v.156, n.2, p.505-520, 2010. Disponível em: <http://mic.sgmjournals.org/ content/156/2/505.short>. Acesso em: 05 jan. 2011. doi: 10.1099/mic.0.034058-0.

CHAGAS Jr., A.F. et al. Produção de ácido indol-acético por rizóbios isolados de caupi. Revista Ceres, Viçosa, v.56, n.6, p.812-817, 2009. Disponível em: <http://www.ceres.ufv.br/ceres/ revistas/V56N006P54109.pdf>. Acesso em: 12 mar. 2010.

CHEN, X.C. et al. Modulating DNA bending affects NodDmediated transcriptional control in Rhizobium leguminosarum. Nucleic Acids Research, Oxford, v.33, n.8, p.2540-2548, 2005. Disponível em: <http://nar.oxfordjournals.org/content/ 33/8/2540.full>. Acesso em: 12 mar. 2010. doi: 10.1093/nar/ gki537.

EDWARDS, U. et al. Isolation and direct complete nucleotide determination of entire genes characterization of a gene coding for 16S-ribosomal RNA. Nucleic Acids Research, Oxford, v.17, n.19, p.7843-7853, 1989. Disponível em: <http:// www.ncbi.nlm.nih.gov/pmc/articles/PMC334891/>. Acesso em: 12 nov. 2005.

GORDON, S.A.; WEBER, P.R. Colorimetric estimation of indolacetic acid. Plant Physiology, Moscow, v.26, n.1, p.192195, 1951. Disponível em: <http://www.plantphysiol.org/ content/26/1/192.full.pdf + html >. Acesso em: 03 mar. 2010. doi: $10.1104 / p p .26 .1 .192$.

GUPTA, C. et al. Plant growth enhancement and suppression of Macrophomina phaseolina causing charcoal rot of peanut by fluorescent Pseudomonas. Biology Fertility Soils, Berlin, v.35, n.6, p.399-405, 2002. Disponível em: <http:// www.springerlink.com/content/jrr $4 \times 4 \times 81$ efu $3 \mathrm{nxk} />$. Acesso em: 03 mar. 2010. doi: 10.1007/s00374-002-0486-0.

MAGUIRE, J.D. Speed of germination-aid in selection for seedling emergence and vigor. Crop Science, Madison, v.2, n.2, p.176-177, 1962. Disponível em: <https://www.soils.org/ publications/cs/abstracts/2/2/CS0020020176>. Acesso em: 03 mar. 2010 .

MATIRU, V.N.; DAKORA, F.D. Potential use of rhizobial bacteria as promoters of plant growth for increased yield in land races of African cereal crops. African Journal Biotechnol, Africa, v.3, n.1, p.1-7, 2004. Disponível em: <https://www.soils.org/ publications/cs/abstracts/2/2/CS0020020176>. Acesso em: 03 mar. 2010 .

OSORIO FILHO, B.D. Rizóbios eficientes em Lotus em condições de estresse hídrico e promotores de crescimento em arroz irrigado. 2009. 113f. Tese (Doutorado em Ciência do Solo) - Curso de Pós-graduação em Ciência do Solo, Universidade Federal do Rio Grande do Sul, Porto Alegre, RS.

PALANIAPPAN, P. et al. Isolation and characterization of plant growth promoting endophytic bacterial isolates from root nodule of Lespedeza sp. Biology Fertility Soils, Berlin, v.46, n.8, p.807-816, 2010. Disponível em: <http:// www.springerlink.com/content/g385407120575151/>. Acesso em: 03 mar. 2010. doi: 10.1007/s00374-010-0485-5.

PANDEY, P. et al. Rhizosphere competent Pseudomonas aeruginosa GRC1 produces characteristic siderophore and enhances growth of Indian mustard (Brassica campestris). Currient Microbiology, New York, v.51, n.5, p.303-309, 2005. Disponível em: <http://www.springerlink.com/content/ u317146546120318/>. Acesso em: 15 mar. 2010. doi: 10.1007/ s00284-005-0014-1.

PERRINE-WALKER, F.M. et al. Infection process and the interaction of rice roots with rhizobia. Journal of Experimental Botany, Oxford, v.58, n.12, p.3343-3350, 2007. Disponível em: 〈http://jxb.oxfordjournals.org/content/58/12/3343.short $\rangle$. Acesso em: 08 fev. 2010. doi: 10.1093/jxb/erm181.

SCHLINDWEIN, G. et al. Influência da inoculação de rizóbios sobre a germinação e o vigor de plântulas de alface. Ciência Rural, Santa Maria, v.38, n.3, p.658-664, 2008. Disponível em: <http://www.scielo.br/scielo.php?pid=S0103$84782008000300010 \&$ script $=$ sci_arttext $>$. Acesso em: $08 \mathrm{fev}$. 2010. doi: $10.1590 / \mathrm{S} 0103-84782008000300010$.

TAMURA, K. et al. MEGA. MEGA4: molecular evolutionary genetics analysis (MEGA) software version 4.0. Molecular Biology and Evolution, Amsterdam, v.24, n.8, p.1596-1599, 2007. Disponível em: <http://mbe.oxfordjournals.org/content/ 24/8/1596.short>. Acesso em: 08 fev. 2010. doi: 10.1093/ molbev/msm092.

TRÜPER, H.G. et al. The prokaryote characterization and identification. In: DWORKIN, M. (Ed.). The prokaryotes a handbook on the biology of bacteria. 3.ed. New York: Springer Science, 2006. 959p.

VARGAS, L.K. et al. Occurrence of plant growth-promoting traits in clover-nodulating rhizobia strains isolated from different soils in Rio Grande do Sul state. Revista Brasileira de Ciência do Solo, Piracicaba, v.33, n.5, p.1227-1235, 2009. Disponível em: <http://www.scielo.br/pdf/rbcs/v33n5/v33n5a16.pdf>. Acesso em: 08 fev. 2010.

WEISBURG, W.G. et al. 16S ribosomal DNA amplification for phylogenetic study. Journal of Bacteriology, Oxford, v.173, n.2, p.697-703, 1991. Disponível em: <http://jb.asm.org/cgi/ content/short/173/2/697>. Acesso em: 08 fev. 2010. 